Uluslararası Mühendislik

Cilt/Volume:11 Sayı/Issue:1 Ocak/January 2019

Araştırma Makalesi / Research Article

\title{
Akıllı Yol Durum Sensörü Tasarımı
}

\section{Intelligent Road Condition Sensor Design}

\author{
Fecir Duran ${ }^{\text {iD }}$, Mustafa Teke ${ }^{2}$ (D) \\ ${ }^{\text {I} G a z i ~ U ̈ n i v e r s i t e s i, T e k n o l o j i ~ F a k u ̈ l t e s i ~ B i l g i s a y a r ~ M u ̈ h e n d i s l i g ̆ i, ~} 06560$ Ankara, TÜRKIYE \\ ${ }^{2}$ Çankırı Karatekin Üniversitesi, Meslek Yüksekokulu Mekatronik Programı,18200 Çankırı, TÜRKIYE
}

Başvuru/Received: 09/01/2019

Kabul/Accepted: 26/01/2019

Son Versiyon/Final Version: 31/01/2019

\begin{abstract}
$\ddot{O} \mathbf{z}$
Bu çalışmada, yol yüzeyinin durumunu tespit eden akıllı yol durum sensörü tasarlanmıştır. Sürücülerin ve yolcuların güvenliğini en çok tehlikeye sokan buzlu yol durumunun tespiti üzerine çalışılmıştır. Yol yüzeyi tahmini için toprak sıcaklığı, hava sıcaklığı, hissedilen nem, hava basıncı ve yol yüzeyindeki iletkenlik değerleri sınıflandırma algoritmalarında öznitelik olarak seçilmiştir. Yol yüzeyi buzlu, kuru, ıslak ve tuzlu-ıslak olarak sınıflandırılmıştır. Sınıflandırma algoritmaları olarak K en yakın komşu ve Destek Vektör Makinası tercih edilmiştir. K en yakın komşu algoritmasının, Destek Vektör Makinası algoritmasına göre daha iyi sonuç verdiği görülmüştür. Sınıflandırıcı tek kartlı bilgisayar olarak bilinen Raspberry Pi3 üzerinde gerçek zamanlı olarak çalsştırılmaktadır. Tasarlanan yol durum sensörü mevcut sensörlere göre kurulumu kolay ve yüksek başarıma sahiptir.
\end{abstract}

\section{Anahtar Kelimeler}

"Makine Öğrenmesi, Yol Durum Sensörü, Gömülü Sistem"

\begin{abstract}
In this study, intelligent road condition sensor is designed to determine the condition of the road surface. It has been studied on the determination of the icy road situation which endangers the safety of drivers and passengers at most. For road surface estimation, soil temperature, air temperature, sensed humidity, air pressure and conductivity values on the road surface are selected as attributes in classification algorithms. The road surface is classified as icy, dry, wet and salty-wet. K-Near Neigbours and Support Vector Machine were preferred as classification algorithms. It is seen that K-Near Neigbours algorithm has given more accurate results than Support Vector Machine algorithm. The classifier is run in real time on the Raspberry Pi3, known as a single board computer. The designed road condition sensor is easy to install and has high performance in comparison with existing sensors.
\end{abstract}

\section{Key Words}

"Machine learning, Road Condition Sensor, Embedded System" 


\section{GíRiş}

Olumsuz hava ve yol koşullarının tahmini hakkında birçok çalışma yapılmıştır. Yol hava durumu bilgi sistemi (RWIS-Road Weather Information Systems) 1980'lerden bu yana kullanılmaktadır. RWIS sürücülere otoyol kenarlarında bilgilendirme yapabilmenin yanı sıra karayolu bakım birimlerine de yol yüzeyindeki kar ve buz hakkında bilgi vermektedir. RWIS altyapısının iki önemli noktası vardır ki bunlar yolculuk güvenliği ve yol bakım maliyetidir. RWIS yardımıyla zamandan ve yol bakım maliyetinden ciddi tasarruf sağlanır. Yol kenarlarına konulan hava istasyonları ile yol ve havanın sıcaklıkları ölçülürken kullanılan kameralar aracılığıyla yol yüzeyindeki buzlanma ve karlanma tespit edilir (Crevier \& Delage, 2001).

Yol yüzeyinde oluşan kar ve buzun tespiti için farklı yaklaşımlar kullanılmıştır. Temassız ve temaslı olmak üzere yol yüzey sınıflandırma çalışmaları iki kategoriye ayrılabilir. Yol istasyonlarına yerleştirilen kamera ve sensörler temaslı grubuna girerken araç üzerine monte edilen sensör ve kameralar temassız sınıflandırıcıya girmektedir. İki sistemde de ya kamera ya da sensör(ses,1sı,1şı) ile algılama teknikleri kullanılmaktadır. Bu metotların etkili çalışabilmesi için güçlü hesaplama makinelerine ve aydınlatma kaynaklarına ihtiyaç duyulmaktadır. Temaslı sistemlerde aydınlatma ve güçlü makineler yol kenarlarındaki istasyonlarda kolaylıkla konumlandırılabilmektedir ancak taşınır sistemlerde bunu gerçekleştirmek zordur. Temassız uzaktan ölçüm sistemlerinde sonic radar, infrared dedektör ve kamera ile görüntü işleme üzerine çalışılmıştır(Gresham ve ark., 2001; Werthof ve ark., 2002). Dalga boyuna duyarlı kameralar yardımıyla karlı, buzlu yol koşullarını belirlemede \%80-90 başarı elde edilirken kuru ve 1slak yol durumu belirlemede \%70'e kadar başarı elde edilmiştir (Kuehnle \& Burghout, 1998). Omer ve Fu (2010) temassız olarak Yol yüzey koşullarını düşük maliyetli GPS ile işaretlenmiş noktalar için görüntü tanıma sistemi yardımıyla tespit edilmektedir. Bu çalışmada karla kaplı yol yüzeyi üstündeki buz tabakasının tespiti mümkün değildir. Bunun yanı sıra yüzey tespitinde de 1şık yoğunluğunun ani değişimi ve yol üzerine düşen gölgelenmeden dolayı yüzey sınıflandırmasında hatalar meydana gelmektedir (Omer \& Fu, 2010). Sass (1997) temassız olarak Danimarka'da karayolu istasyonlarında kaygan yol koşullarına etki eden yol yüzey sıcaklığını otomatik öngören sistem sunmuştur. Yol yüzeyine maruz kalan güneş 1şınımının etkisini incelemiştir. Sayısal tahmin ile atmosferik veriler istasyondan alınarak yol yüzeyi hakkında tahminde bulunulmuştur. Sayısal model ile yol yüzey sıcaklık tahmini sistemi geliştirmiştir. Atmosferik veriler ile yapılan tahmin sonucu yol yüzeyi hakkında genel tespitte bulunulmuştur ancak yol yüzey durumu bölgesel olarak değişen konumlarda bu sistem yeterli olmamaktadır. Gagnon ve arkadaşları(2012) yol yüzey koşullarının ölçülmesi için Optik tabanlı teknolojilerden de faydalanılarak sürücüler için uyarı sistemi tasarlanmıştır. Optik sistemlerde ışı̆̆ın yansıması ya da soğurulmasına dayalı yöntemler geliştirilmiştir. Ancak bu yöntemler gizli buzlanma gibi içerisinde hava kabarcığı bulunmayan buzlanmalarda doğru sonuç vermemektedir. Yansıma metodunda yansıyan yüzey içerisindeki hava kabarcıklarının bulunmasıyla buz katmanı hakkında yorum yapılmaktadır. İnce film tabakası şeklinde oluşan buzlanmalarda bu yöntem çalışmamaktadır (Gagnon, Groves, \& Pearson, 2012). Casselgren ve ark. (2016) NIR(Near InfraRed) kamera ölçüm tekniği ile anlık yol yüzey koşulunu tespit etmiştir. Ancak kurulan sistem hem ekonomik hem de uygulanabilir değildir (Casselgren, Rosendahl, Sjödahl, \& Jonsson, 2016). Jonsson ve ark. (2015) k1zıl ötesi kamera sistemi ile yol yüzeyi sınıflandırılması yapmıştır. K en yakın komşu (K-Near Neigbours-KNN) metodunun Destek Vektör Makinasından (Support Vector Machine-SVM) daha kullanışlı olduğunu öne sürmüştür. Kullanılan cihazların boyut ve maliyeti çok yüksek olduğundan uygulanabilirliği konusunda sıkıntılar mevcuttur (Jonsson, Casselgren, \& Thörnberg, 2015).

Bu çalışmada, yüksek doğrulukla çalışan ve düşük maliyetli yol yüzey durum tahmin sistemi gerçekleştirilmiştir. Sistemde KNN ve SVM algoritmaları kullanılmıştır. Yol yüzey durumunu tahmin etmek için KNN algoritması seçilmiştir ve yol yüzey sıcaklığı, yolun $10 \mathrm{~cm}$ alt sıcaklığı, mutlak nem ve hava basıncı verilerini kullanmaktadır. Tahmin algoritması Raspberry Pi3 gömülü sistem platformu üzerinde gerçek zamanlı olarak çalışmaktadır. KNN algoritmasıyla yüksek başarıma sahip sonuçlar elde edilmiştir.

\section{MATERYAL VE METHOD}

\subsection{Donanım Yapısı}

Akıllı yol durum sensörü, iletkenlik, sıcaklık, nem ve basınç sensörleri ile Raspberry Pi3'den oluşmaktadır. Sistemin genel yapısı şekil 1'de görülmektedir.

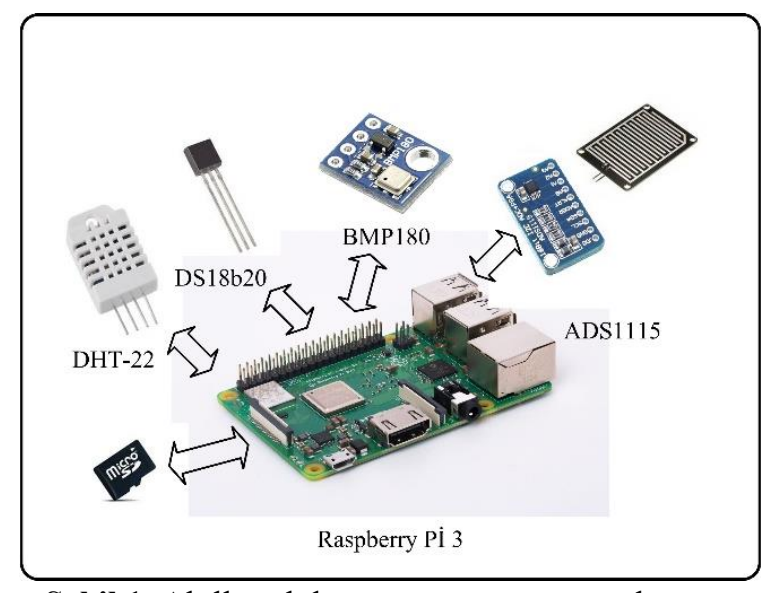

Şekil 1. Akıllı yol durum sensörünün genel yapısı 
Buzlanmanın en önemli sebeplerinden biri yol yüzey sıcaklığının sıfır derece veya altında olması ve havanın neminin yüksek olmasıdır (Harvey, McLinden, \& Tew, 2013). Bu nedenle yollardaki buzlanmanın oluşumunun tespiti ve tahmini için bu verilerin ölçülmesi çok önemlidir. Gerçekleştirilen sistemde yol sıcaklığını ve havanın nemini ölçmek için DHT-22 sensörü kullanılmaktadır. DHT-22 sensörü \%0-100 oranında nem değerini \%2-5 doğrulukta ölçmenin yanı sıra $-40^{\circ} \mathrm{C}$ ile $80^{\circ} \mathrm{C}$ arasında sıcaklık ölçümü yapabilen sıcaklık ve nem sensörüdür. Yol yüzeyine yakın seviyeye yerleştirilen DHT-22 sensörü hava sıcaklığını ve havanın nem miktarını anlık olarak okuyarak algoritmaya giriş verisi olarak işleme alınmaktadır. Şekil 2c'de DHT-22 gösterilmektedir. Buzlanmayı etkileyen diğer bir fiziksel büyüklük de hava basıncının değişimleridir. Hava basıncının artmasıyla donma noktası düşerken kaynama noktası da aynı oranda artmaktadır. Yol yüzeyinde oluşacak olan buz tabakası için hava sıcaklığının yanı sıra hava basınç miktarı da tahmin algoritması için önemlidir. Sistemde düşük güç tüketimine sahip BMP-180 dijital hava basıncı sensörü kullanılmıştır. 300-1100 hPa aralığındaki hava basıncını ölçmektedir. SBC ile I2C (Inter-Integrated Circuit) protokolü aracılığıyla haberleşmektedir. Şekil 2d'de gösterilmektedir. I2C protokolü SDA (Serial Data Line) ve SCL (Serial Clock) hatlarından oluşan eşzamanlı haberleşmeye örnektir. SDA cihazlar arasındaki veri yolunu ifade ederken, SCL veri iletimindeki senkronizasyonu sağlayan saat darbelerini ifade etmektedir. Toprak sıcaklığı, yol yüzeyinin sıcaklığını etkilemesinden dolaylı yolun buzlanmasını etkiler. Gerçekleştirilen çalışmada toprak altı sıcaklığının ölçümü için şekil 2b'de görülen DS18B20 sensörü kullanılmıştır. DS18B20 dijital çalışan 12-bit yüksek çözünürlüğe sahip sıcaklık sensörüdür. $-55^{\circ} \mathrm{C}$ ile $+125^{\circ} \mathrm{C}$ arasındaki sıcaklık ölçümlerini yapabilmektedir. Tek hat haberleşme protokolü aracılığıly tek bir hat üzerinden Raspberry Pi3 ile haberleşmektedir. Tek hat haberleşmesi I2C protokolüne benzeyen daha düşük veri hızına sahip haberleşme protokolüdür. Şekil 2a'da gösterilen Raspberry Pi3 üzerinde genel amaçlı giriş-çıkış birimine, HDMI çıkışa, USB bağlantısına, 1GB RAM hafızasına, mikro SD hafıza kartı yuvasına, ethernet modülüne, wi-fi modem ve güçlü bir işlemci serisi olan ARM işlemcisi bulundurmaktadır. Secure Digital (SD) flash bellek kartı takılarak işlemciyle uyumlu bir sürücü olarak çalışmaktadır. Raspbian açık kaynak ve kurulumu ücretsiz olan bir işletim sistemidir. Raspberry Pi3 çok fonksiyonlu esnek yapılı programlama ve elektronik proje tasarımına uygun bir gömülü sistemdir. Bu özellikleri Raspberry Pi3'ü kablosuz sensör düğümü olarak kullanmayı kolaylaştırır. İnternet veya grafik arayüz gerektiren, sensör dügümü gibi projelerde bahsedilen bütün bu özellikler Raspberry Pi3'ün tercih sebebidir. Buna ek olarak sınıflandırma, akıllı sistemler gibi yüksek performanslı makine gerektiren işlemleri üzerinde yaparak veri işlemek için başka bir sunucuya veri taşıma zahmetinden kurtarmaktadır. Yol yüzeyine yapay yollarla serpilen tuz yolun buzlanma derecesini düşürecektir. Bu nedenle yol yüzeyindeki tuzluluğun ölçülmesi doğru bir tahmin için gereklidir. Üzerinde analog dijital çevirici (ADC) bulunmayan mikrodenetleyicilerde ya da düşük çözünürlüklü ADC’ye sahip olan sistemlerde kullanılabilen analog sinyal ölçüm sensörüdür. ADS1115 sensör kartı, 4 adet 16-bit yüksek çözünürlüklü analog sinyali digital sinyale dönüştürmeye ve saniyede 860 örnekleme alma hızına sahiptir. Küçük işaretlerle uğraşanlar için içerisinde amplifikatör bulundurmaktadır. 2V-5V arası çalışma gerilimine sahiptir. I2C haberleşme protokolünü kullanarak Pi3 ile haberleşmektedir. 4 farklı adres alabilen kart ile aynı anda 4 kart sisteme ilave edilebilir bu sayede toplamda 16 adet ADC aynı anda çalışabilmektedir. Şekil 2e'de gösterilmektedir. Gerçekleştirilen çalışmada yoldaki tuz oranının tespiti için kullanılmaktadır. Yol yüzeyine yerleştirilen iletken teller arasındaki direnç okunarak yol yüzeyinin tuzlanmış olduğu belirlenmektedir.

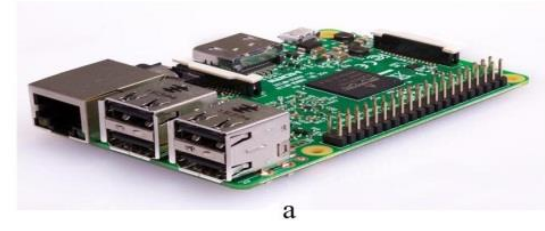

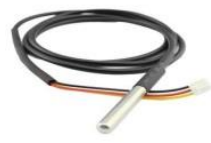

b

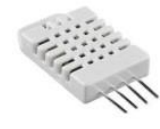

$\mathrm{c}$

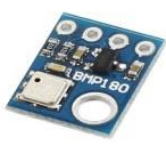

d

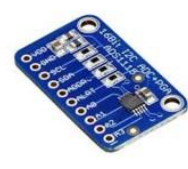

$\mathrm{e}$

Şekil 2. (a) Raspberry Pi3; (b) DS18B20 S1caklık sensörü; (c) DHT-22; (d) BMP180; (e) ADS1115 Analog çevirici

\subsection{Yazılım Yapısı}

Tasarlanan sistemde ilk aşama olarak sınıflandırma yapabilmek için gerekli olan eğitim verisi toplamıştır. Sonrasında toplanan verilerden yüksek oranda doğru tahmin yapabilmek için en uygun alt veri kümesi seçilmiştir. Son aşamada ise yol durum tahmini Raspberry Pi3 ile gerçekleştirilmektedir.

$\mathrm{Bu}$ çalışmadaki sistemde yol ve hava durum verileri anlık okunarak daha önceden kayıt altına alınan veriler ile sınıflandırma algoritmasına sokulur. Çevre birimlerden aldığı anlık sensör bilgileri ile geçmişte kaydettiği bilgiler arasında sınıflandırma algoritması kullanarak yol yüzey durum tahmini yapılmıştır. Sınıflandırma işleminde en yakın komşu ve destek vektör makinesi algoritmaları kullanılmıştır

Yol durum sınıflandırması için özellik seçiminde yenilemeli özellik seçimi (recursive feature elimination-RFE) yöntemi kullanılmıştır. Yenilemeli özellik seçimi algoritmasının seçimi sonucunda en iyi özellik listesi oluşturulur. Yenilemeli özellik seçimi özellik sıralama doğruluğu kullanılan sınıflandırma modeline bağlıdır. Buna bağlı olarak da seçilen özellik alt kümesi de daha iyi performans gösterecektir. Yenilemeli özellik seçimi de seçilen alt gruplar, değerlendirme fonksiyonuna göre karşılaştırılır. Adım N + 1'de seçilen alt küme, adım N'de seçilen altkümeden daha yüksek doğrulukta sonuç verirse, $\mathrm{N}+1$ adımında seçilen alt küme sınıflandırma için kullanılacak uygun kümedir (Guyon, Weston, Barnhill, \& Vapnik, 2002). Bu çalışmada akıllı pasif yol durum sensörü olan IRS31 ve hava durumu ölçüm istasyonu hava durumu ölçen WS600 eğitim veri seti oluşturmada kullanılmıştır. Veri seti içerisinde yolun alt sıcaklığı, üst sıcaklı̆̆ tuzluluk oranı, rüzgâr hızı, rüzgâr yönü ve hava basıncı gibi veriler bulunmaktadır. Sınıf kümesi olarak da 1slak-tuzlu, kuru, 1slak ve buzlu yol durumları bulunmaktadır. Yüksek doğruluk veren yeni özellik alt kümesi yolun alt sıcaklığı, hava sıcaklığı, nem 
miktarı, yol yüzey tuzluluk oranı ve hava basıncı değerleridir. Özellik seçim algoritmasında en yüksek doğruluk skorlarını alan özellikler alt küme olarak seçilmiştir.

\subsection{KNN Algoritması}

KNN daha önce sınıflandırılmış veri kümesine ait noktalar ile sınıflandırılmamış yeni noktanın hangi kümeye ait olduğunu belirler. Sınıflandırma işlemini, sınıflandırılacak yeni noktaya en yakın k tane uzaklıktaki noktaların sınıf yoğunluğuna bakarak yapar. Bu sınıflandırma algoritması bilinen eski, basit ve etkili makine öğrenmesi algoritmalarındandır (Batista \& Silva, 2009; Bhatia, 2010; Cover \& Hart, 1967). KNN algoritması sınıflandırma yaparken eğitime ihtiyaç duymaması, gürültülü veri setine karşı hassas olmaması güçlü taraflarındandır (Bhatia, 2010). Aşııı bellek kullanımı, nitelik sayısı ve özellik sayısı artması ile işlem yükünün artması hesaplama yükünde artma meydana gelmesi zayıf yanıdır. Hesaplama yüküne seçilen $\mathrm{k}$ değeri ve uzaklık ölçütü de etki etmektedir (Liu \& Zhang, 2012). KNN algoritmasının performansı örnek veri setleri arasındaki uzaklığın ölçülmesine de bağlıdır. Veri setleri arasındaki yakınlığı Öklid, Minkowski, Manhattan ve Chebyschev gibi uzaklık ölçütleri ile hesaplanabilir (Kresse \& Danko, 2012; Xu, Zong, \& Yang, 2013). Tasarımı yapılan sistemde k=3 değeri ve Öklid uzaklık ölçütü ile yapılan sınıflandırmada en yüksek tahmin oranını vermiştir. Sistemin hesaplama yükünü azaltmak için sınıflandırma öncesi öznitelik seçimi yapılarak boyut azaltma işlemi yapılmıştır. Bu sayede sistemin daha hızlı cevap vermesi sağlanmıştır.

\subsection{SVM Algoritması}

SVM algoritması istatistiksel yaklaşıma göre çalışan sınıflandırma algoritmalarındandır. SVM'nin ilk uygulaması iki sınıfa sahip veri kümelerinin hangi sınıfa ait olduğunu belirlemek için çalışılmıştır. İki sınıflı problemlerdeki başarısının ardından çok sınıflı ve doğrusal olmayan verilerin sınıflandırılması üzerine uğraşılmıştır. SVM'nin temel mantığı ayrılması istenen sınıflar arasında mesafesi en geniş boşluğu ya da düzlemi belirlemesi ya da tahmin etmesidir bu düzleme hiper-düzlem denilmektedir (Vapnik, 1995). Makine öğrenmesi algoritmalarından SVM neredeyse çoğu alanda kullanıldığı gibi akıllı ulaşım sistemlerinde de kullanılmaktadır. Şekil 3a'da gösterildiği gibi iki sınıf arasında sonsuz adet düzlem çizilebilmektedir. Oluşturulan bu düzlemlerden iki sınıfın arasındaki en büyük ayrımı gösteren düzlem istenilen uygun değerde düzlemdir, sınıf aralığını belirten vektörler ise destek vektörleri olarak bilinir ve şekil 3b'de gösterilmektedir. Sınıflar arası optimum hiper düzlem şekil 3c'de gösterildiği gibi belirlenmektedir.

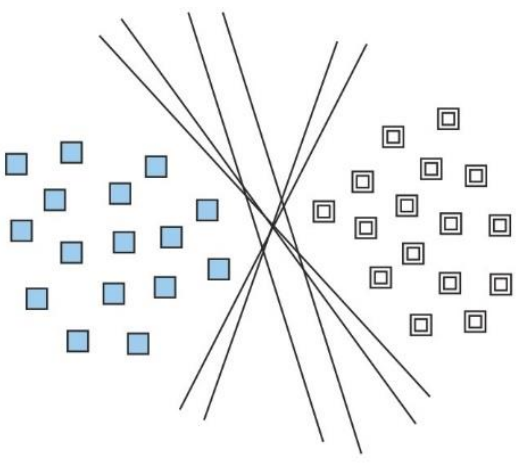

a

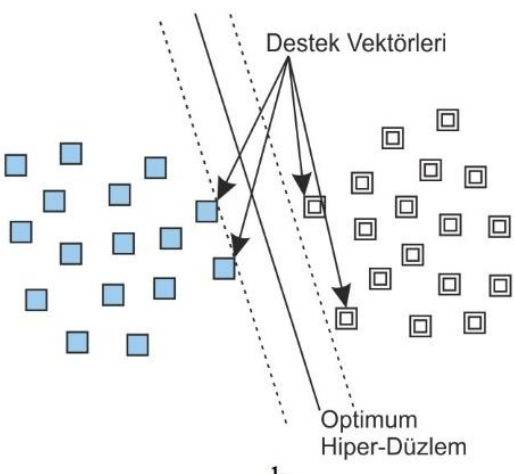

$\mathrm{b}$

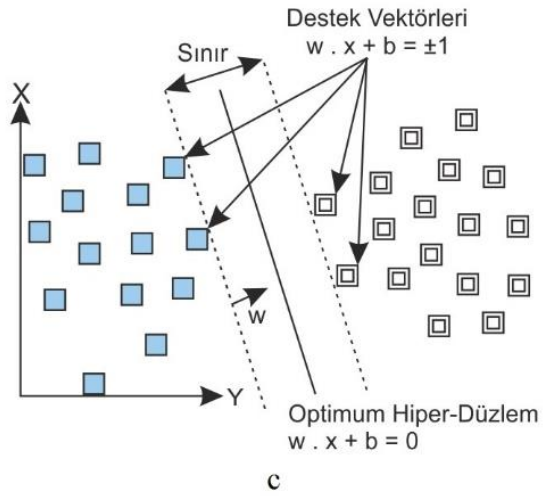

$\mathrm{c}$

Şekil 3. (a) iki sınıf arasındaki sonsuz düzlem (b) destek vektörler (c) optimum hiper düzlem

SVM'nin eğitimi için $n$ sayıda örnekten oluşan eğitim verisinin $\left\{x_{i}, y_{i}\right\}, i=1, \ldots, n$ olsun. Doğrusal olarak iki sınıfın bir yüzeyle ayrılabilme durumunda düzlemin denklemi eşitlik 1'deki gibi olur.

$$
f(x)=w^{t} \cdot x+b=\sum_{i=1}^{n} w_{i} x_{i}+b
$$

Denklemde w ağırlık vektörünü yani düzlemin normalini, b sabiti sapma değerini gösterirken bu değişkenlerin değerleri düzlemin konum pozisyonunu değiş̧tirmektedir. SVM'de sınıflar doğrusal ayrılabiliyorsa $y_{i}=+1$ ve $y_{i}=-1$ etiketli sınıflara aynı uzaklıkta ayıran en iyi düzlemin bulunmasıdır. Eğitim kümesinin aşağıdaki denklemleri sağlaması durumunda;

$\mathrm{y}_{\mathrm{i}}=+1$ için $\mathrm{w}^{\mathrm{t}} \cdot \mathrm{x}_{\mathrm{i}}+\mathrm{b} \geq+1$

$\mathrm{y}_{\mathrm{i}}=-1$ için $\mathrm{w}^{\mathrm{t}} \cdot \mathrm{x}_{\mathrm{i}}+\mathrm{b} \leq-1$

Bu hiper-düzlemleri meydana getiren destek vektörleri w. $x_{i}+b= \pm 1$ şeklinde ifade edilirler. En uygun düzlemin sınırının maksimum olabilmesi için $\|\mathrm{w}\|$ minimum olmalıdır. Buna bağlı olarak sınırlar ise $\mathrm{y}_{\mathrm{i}}\left(\mathrm{w} \cdot \mathrm{x}_{\mathrm{i}}+\mathrm{b}\right)-1 \geq 0$ ve $\mathrm{y}_{\mathrm{i}} \in\{1,-1\}$ ifade edilir. $\mathrm{Bu}$ optimizasyon eşitliği Lagrange denklemleri aracılığıyla çözümlenebilir ve eşitliğin son hali aşağıdaki şekli almaktadır. (Marsland, 2011). 


$$
L(w, b, a)=\frac{w^{2}}{2}-\sum_{i=1}^{n} a_{i} y_{i}\left(w \cdot x_{i}+b\right)+\sum_{i=1}^{n} a_{i}
$$

\section{DEĞERLENDİRME}

Akıllı ulaşım sistemleri için tasarlanan yol durum sensörü yol yüzey sıcaklığını, hava sıcaklığını, hissedilen nemi, hava basıncını ve yol yüzeyindeki tuz miktarını anlık olarak işleme almaktadır. Yol yüzeyindeki buzlanmayı etkilediği için yolun $10 \mathrm{~cm}$ altındaki sıcaklık değeri de algoritmada işleme alınmıştır. Yol yüzeyinin buz tutabilmesi için yol altının da sıcaklığı düşük değerlerde olmalıdır. Kış mevsiminde güneşlenmesi az, eğimi olan ve keskin viraja sahip bir konumdan eğitim veri seti toplanmıştır. Bölgesel hava durumu verilerinin genel meteorolojik verilere yakın olduğu ama riskli bölgeden alınan verilerin genel hava verilerinden farklı olduğu görülmüştür. KNN ve SVM algoritmalarına girilen veri seti KNN algoritmasında daha doğru sonuç vermektedir. Karışıklık matrisinin diyagonali algoritmanın doğruluk oranı hakkında bilgi vermektedir. Karışıklık matrisi yatayda gerçek sınıf değerlerini düşeyde tahmin edilen sınıf değerlerini barındıran bir kare matristir. Matrisin diyagonal değerleri doğru sonuçların toplamını vermektedir. Sadece bu değere bakarak da sınıflandırma algoritmasının performansı hakkında bilgi edinilebilir (Marsland, 2011).

Nem, hava sıcaklığı, yol sıcaklığı ve iletkenlik sensörlerinden alınan anlık veriler KNN algoritmasında işleme alınarak \%99.68 oranında başarım elde edilmiştir. Sınıflandırıcı değerlendirmesi yapmak için karışıklık matrisinden yararlanılmıştır ve algoritma cevapları tablo 1'de gösterilmiştir.

Tablo 1. K-en yakın komşu ve Destek vektör makinesi algoritmalarının karışıklık matrisi sonuçları

\begin{tabular}{|c|c|c|c|c|c|c|c|c|c|}
\hline KNN & Buzlu & Kuru & Islak & Tuzlu-Islak & SVM & Buzlu & Kuru & Islak & Tuzlu-Islak \\
\hline Buzlu & 1284 & 4 & 0 & 0 & Buzlu & 1167 & 121 & 0 & 0 \\
\hline Kuru & 9 & 6048 & 0 & 2 & Kuru & 31 & 6028 & 0 & 0 \\
\hline Islak & 0 & 2 & 102 & 3 & Islak & 0 & 107 & 0 & 0 \\
\hline $\begin{array}{l}\text { Tuzlu- } \\
\text { Islak }\end{array}$ & 0 & 3 & 2 & 541 & $\begin{array}{l}\text { Tuzlu- } \\
\text { Islak }\end{array}$ & 3 & 515 & 0 & 28 \\
\hline
\end{tabular}

Karışıklık matrisinden doğruluk oranı, hassasiyet, yaygınlık gibi değerler hesaplanabilmektedir. Diyagonal değerlerinin toplamının bütün değerlere oranı doğruluk oranını vermektedir. Bu çalışmada kullanılan sınıflandırıcıların performansı doğruluk oranına göre kıyaslanmaktadır ve eşitlik 5'de gösterilmektedir.

$$
\begin{aligned}
& \text { Doğruluk Oranı }=\frac{\text { Doğru Pozitif }+ \text { Doğru Negatif }}{\text { Doğru Pozitif }+ \text { Doğru Negatif }+ \text { Yanlış Pozitif }+ \text { Yanlış Negatif }} \\
& \text { KNN D. O. }=\frac{1284+6048+102+541}{1284+6048+102+541+4+11+5+5}=\% 99.68 \\
& \text { SVM D. O. }=\frac{1167+6028+0+28}{1167+6028+0+28+121+31+107+518}=\% 90.28
\end{aligned}
$$

Yukarıdaki matrislerin diyagonal değeri en büyük olan KNN algoritmasıdır. Tasarlanan yol durum sensöründe KNN algoritması tercih edilmiştir.

\section{SONUÇ}

Tasarlanan yol durum sensörü hali hazırda bulunan temaslı yol durum sensör kurulumundan daha etkindir yüksek doğrulukta çalışmaktadır. Harici bir bilgisayar donanımına ihtiyaç duymaksızın yol yüzeyi hakkında tahmin yapabilmektedir. Raspberry Pi3 kullanılarak tasarlanan sistem, yol yüzey sıcaklığını, hava sıcaklığını, algılanan nemi, hava basıncını ve yol yüzeyindeki tuz miktarını gerçek zamanlı olarak kaydedebilmektedir. Toplanan veriler, \%99.68 performans oranı elde edilen KNN algoritmasına uygulanmakta ve yol yüzey durumu tahmin edilmektedir. İşlenmiş veri setindeki en doğru sınıflandırma KNN sınıflandırıcısıdır. Bu algoritma ile Raspberry Pi3 de hızlı ve kesin cevap veren bir yol durum sensörü geliştirilmiştir.

\section{REFERANSLAR}

Batista, G., \& Silva, D. F. (2009). How k-nearest neighbor parameters affect its performance. Paper presented at the Argentine symposium on artificial intelligence.

Bhatia, N. (2010). Survey of nearest neighbor techniques. arXiv preprint arXiv:1007.0085.

Casselgren, J., Rosendahl, S., Sjödahl, M., \& Jonsson, P. (2016). Road condition analysis using NIR illumination and compensating for surrounding light. Optics and lasers in engineering, 77, 175-182. 
Cover, T., \& Hart, P. (1967). Nearest neighbor pattern classification. IEEE transactions on information theory, 13(1), 21-27.

Crevier, L.-P., \& Delage, Y. (2001). METRo: A new model for road-condition forecasting in Canada. Journal of Applied Meteorology, 40(11), 2026-2037.

Gagnon, R., Groves, J., \& Pearson, W. (2012). Remote ice detection equipment-RIDE. Cold Regions Science and Technology, $72,7-16$.

Gresham, I., Jain, N., Budka, T., Alexanian, A., Kinayman, N., Ziegner, B., . . . Staecker, P. (2001). A compact manufacturable 76-77-GHz radar module for commercial ACC applications. IEEE Transactions on Microwave Theory and Techniques, 49(1), 4458.

Guyon, I., Weston, J., Barnhill, S., \& Vapnik, V. (2002). Gene selection for cancer classification using support vector machines. Machine learning, 46(1-3), 389-422.

Harvey, A. H., McLinden, M. O., \& Tew, W. L. (2013). Thermodynamic analysis and experimental study of the effect of atmospheric pressure on the ice point. Paper presented at the AIP Conference Proceedings.

Jonsson, P., Casselgren, J., \& Thörnberg, B. (2015). Road surface status classification using spectral analysis of NIR camera images. IEEE Sensors Journal, 15(3), 1641-1656.

Kresse, W., \& Danko, D. M. (2012). Springer handbook of geographic information: Springer Science \& Business Media.

Kuehnle, A., \& Burghout, W. (1998). Winter road condition recognition using video image classification. Transportation Research Record: Journal of the Transportation Research Board(1627), 29-33.

Liu, H., \& Zhang, S. (2012). Noisy data elimination using mutual k-nearest neighbor for classification mining. Journal of Systems and Software, 85(5), 1067-1074.

Marsland, S. (2011). Machine learning: an algorithmic perspective: Chapman and Hall/CRC.

Omer, R., \& Fu, L. (2010). An automatic image recognition system for winter road surface condition classification. Paper presented at the Intelligent transportation systems (itsc), 2010 13th international ieee conference on.

Sass, B. H. (1997). A numerical forecasting system for the prediction of slippery roads. Journal of Applied Meteorology, 36(6), 801-817.

Vapnik, V.N., 1995, The Nature of Statistical Learning Theory, Springer-Verlag, New York.

Werthof, A., Siweris, H., Tischer, H., Liebl, W., Jaeger, G., \& Grave, T. (2002). A 38/76 GHz automotive radar chip set fabricated by a low cost PHEMT technology. Paper presented at the Microwave Symposium Digest, 2002 IEEE MTT-S International.

Xu, G., Zong, Y., \& Yang, Z. (2013). Applied data mining: CRC Press. 